\title{
Biometric Signature
}

National Cancer Institute

\section{Source}

National Cancer Institute. Biometric Signature. NCI Thesaurus. Code C142406.

A verified characteristic mark of an individual's identity based on measurement of the individual's unique physical feature(s) or repeatable action(s). 